\title{
Rapid Detection Tool for Vancomycin-Resistant Enterococcus (VRE) Directly from Human Specimens
}

\author{
Stephen C. Edberg1,2 \\ ${ }^{1}$ Mt. Sinai Health System, New York, NY, USA \\ ${ }^{2}$ Yale University School of Medicine, New Haven, CT, USA \\ Email: stephen.edberg@yale.edu
}

Received 17 July 2014; revised 15 August 2014; accepted 10 September 2014

Copyright (C) 2014 by author and Scientific Research Publishing Inc.

This work is licensed under the Creative Commons Attribution International License (CC BY). http://creativecommons.org/licenses/by/4.0/

(c) (i) Open Access

\begin{abstract}
A new, simple, and one-step tool for the direct detection of vancomycin-resistant Enterocococcus (VRE) EPI-V ${ }^{\circledR}$ (Pilots Point LLC, Sarasota, FL) is presented. It contains all the ingredients in a unique stable powder form in a standard test tube. One only needs to add water, inoculate the specimen, and incubate. Specimens consisted of 553 sequential human rectal/perirectal swabs for VRE surveillance. The presence of VRE was denoted by the production of two sequential color changes corresponding to growth in bile-esculin and production of a positive PYR reaction. The EPI-V ${ }^{\circledR}$ tool was compared to reference VRE detection methods. EPI-V ${ }^{\circledR}$ showed a sensitivity of $102 \%$ and a specificity of $98.4 \%$ for the detection of VRE. The EPI- ${ }^{\circledR}$ tool offers significant advantages: no skilled technologist time required, simple quality control, highly conserved incubator and refrigerator space, and low cost.
\end{abstract}

\section{Keywords}

VRE, Stool, Carriage, Detection

\section{Introduction}

Both asymptomatically colonized and infected patients serve as reservoirs for transmission of VRE, as well as contaminated surfaces and patient care equipment. European Union and United States public health agencies have developed recommendations for preventing the transmission of vancomycin resistance within and among hospitals and nursing homes. Current surveillance methods require a number of sequential steps and need a special series of culture media and identification tests. A highly skilled and trained medical technologist is needed 
to perform the analysis.

A new, simple, and one-step tool for the detection of VRE (as defined as a minimum inhibitory concentration (MIC) to vancomycin of $6 \mathrm{mcg} / \mathrm{mL}$ ) directly from rectal/perirectal specimens was compared to a reference, or to predicate method (Food and Drug Administration (FDA)). The tool (EPI-V ${ }^{\circledR}$ Pilots Point LLC, Sarasota, FL) contains all the required ingredients in a stable powder form, in a standard test tube. The presence of VRE in the rectal swab is denoted by the production of a two sequential biochemical reactions inside the test tube: substrate hydrolysis representing bile-esculin followed by PYR substrate hydrolysis. Bile-esculin plus PYR is the generally accepted identification of the genus Enterococcus [1]-[13].

\section{Material and Methods}

Specimens consisted of 553 sequential human rectal/perirectal surveillance swabs obtained as part of the ongoing surveillance program. The collection device was a Culturette ${ }^{\mathrm{TM}}$ II (Becton Dickinson and Company, Cockeysville, MD). There was no prior notification of individuals collecting the specimens. The Culturette ${ }^{\mathrm{TM}}$ II swab was twirled vigorously in $1 \mathrm{~mL}$ of $\mathrm{pH}$ 7.0, $50 \mathrm{mM}$ HEPES (Sigma-Aldrich, St. Louis, MO) buffer so that each of the two methods would be challenged with the same inoculum.

\section{Standard Culture Method}

The FDA predicate VRE culture method is Bile Esculin Azide agar with $6 \mathrm{mcg} / \mathrm{mL}$ vancomycin (BEAV) (Remel, Lenexa, KS) [http://www.accessdata.fda.gov/cdrh_docs/reviews/K091025.pdf]. From the HEPES buffer, $0.1 \mathrm{~mL}$ of the extracted patient specimen was plated on the surface of the BEAV agar plate. After incubation for 24 hours at $35^{\circ} \mathrm{C}$ in ambient air, colonies that were brown-black were gram stained. Colonies showing gram positive cocci in chains were then tested by the PYR reaction (Becton, Dickinson and Company, Cockeysville, MD). The MIC to vancomycin from PYR positive colonies was performed by the Etest ${ }^{\circledR}$ method (bioMérieux, Durham, NC).

\section{EPI-V ${ }^{\circledR}$}

The EPI- $\mathrm{V}^{\circledR}$ tool is in a powder format, in a flange-capped test tube, and stored at room temperature. To use, 3 $\mathrm{mL}$ of sterile water was added to dissolve the powder. To this solution, $0.1 \mathrm{~mL}$ of the extracted patient's specimen was added. EPI- $\mathrm{V}^{\circledR}$ test tubes were incubated for a maximum of 24 hours at $35^{\circ} \mathrm{C}$ in ambient air to call a specimen negative. However, color development at any time, denoted a positive result. Test tubes demonstrating a brown-black color (bile-esculin positive) were tilted to coat the disk present in the EPI-V ${ }^{\circledR}$ cap. This cap contains an enhanced reagent for the detection of PYR hydrolysis [14]-[17]. The development of a bright fuchsia color within 15 seconds is a positive reaction for PYR. Positive bile-esculin and PYR results demonstrated the presence of VRE (see Figure 1 and Figure 2).

In order to determine if a false-positive or false-negative reaction had occurred from the EPI-V ${ }^{\circledR}$, approximately $0.1 \mathrm{~mL}$ was subcultured from all tests tubes to the surface of a Bile Esculin Azide agar plate containing 6 $\mathrm{mcg} / \mathrm{mL}$ vancomycin. Plates were incubated at $35^{\circ} \mathrm{C}$ for 24 hours in ambient air. All colonies compatible with Enterococcus were then identified to species. If an Enterococcus species was isolated, an Etest ${ }^{\circledR}$ MIC to vancomycin was performed. All isolates were identified to species using the Vitek II system (bioMérieux, Durham, NC).

\section{Results}

The EPI- $\mathrm{V}^{\circledR}$ tool, from a diluted specimen, demonstrated a sensitivity of $102 \%$ and a specificity of $98.4 \%$. Table 1 presents the comparison of the EPI- $\mathrm{V}^{\circledR}$ results versus the Bile Esculin Azide with $6 \mathrm{mcg} / \mathrm{mL}$ vancomycin (BEAV) culture method for 553 stool samples. Table 2 presents the time course of the 250 positive analyses by the EPI-V ${ }^{\circledR}$ tool.

\section{Discussion}

The EPI-V ${ }^{\circledR}$ tool showed excellent sensitivity and specificity relative to the Bile Esculin Azide FDA referenced method and required only a maximum of 20 hours. In addition, the EPI- $\mathrm{V}^{\circledR}$ tool offered several significant ad- 


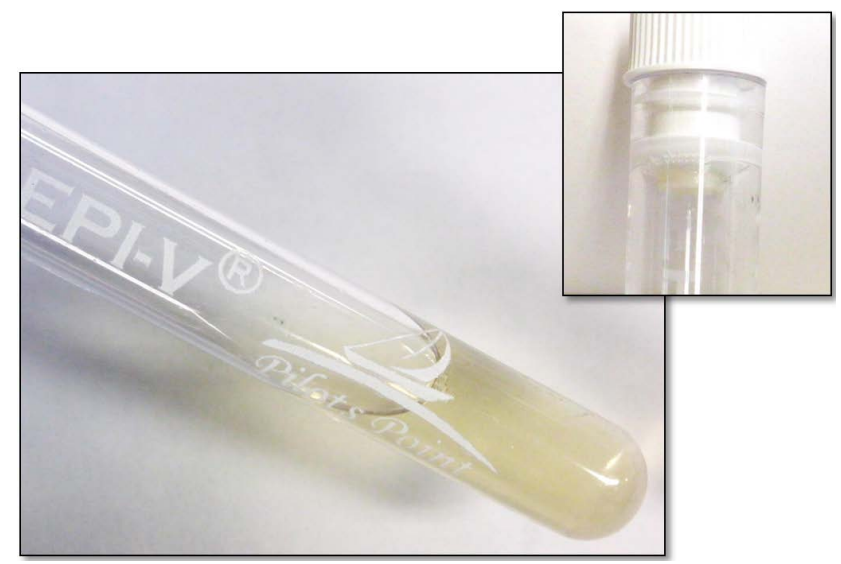

Figure 1. Negative EPI-V ${ }^{\circledR}$. Negative EPI- ${ }^{\circledR}$ liquid is strawcolored and the disk in the cap is white.

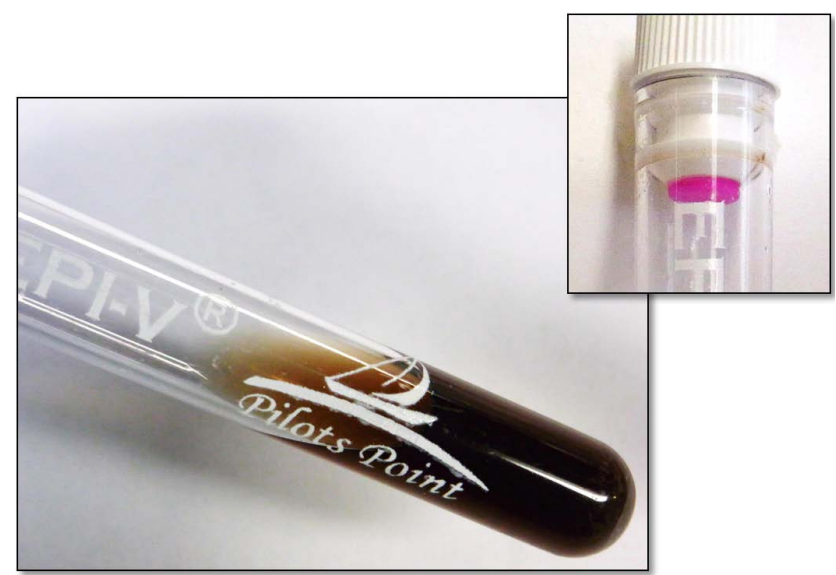

Figure 2. Positive EPI-V ${ }^{\circledR}$. Positive EPI-V ${ }^{\circledR}$ liquid is dark brown-black and the disk in the cap is bright fuchsia.

Table 1. Comparison of EPI-V ${ }^{\circledR}$ and Bile Esculin Azide media for the recovery of VRE from stool samples.

\begin{tabular}{|c|c|c|}
\hline & BEAV positive & BEAV negative \\
\hline EPI-V ${ }^{\circledR}$ positive & 250 & 16 \\
\hline EPI- $V^{\circledR}$ negative & 7 & 280 \\
\hline
\end{tabular}

Table 2. Time to positive of EPI- ${ }^{\circledR}$ from 250 positive stool samples.

\begin{tabular}{ccc}
\hline Time & Number of specimens positive & Cumulative number of specimens positive \\
\hline $5 \mathrm{~h}$ & 22 & 22 \\
$6 \mathrm{~h}$ & 26 & 48 \\
$7 \mathrm{~h}$ & 15 & 63 \\
$8 \mathrm{~h}$ & 21 & 84 \\
$9 \mathrm{~h}$ & 33 & 117 \\
$10 \mathrm{~h}$ & 17 & 134 \\
$16 \mathrm{~h}$ & 83 & 217 \\
$18 \mathrm{~h}$ & 18 & 235 \\
$20 \mathrm{~h}$ & 15 & 250 \\
\hline
\end{tabular}


vantages over the FDA referenced method. These included: no skilled technologist time required, simple quality control, highly conserved incubator and refrigerator space, and approximately 1/4 - 1/3 cost of agar based methods. The simplicity and ease of use of the EPI- $\mathrm{V}^{\circledR}$ epidemiology tool allows for more efficient and timely processing of large numbers of patient surveillance specimens for VRE. This new tool offers the clinical microbiologist, hospital epidemiologist, or infection control practitioner, flexibility as to the timing of collection and number of rectal or perirectal patient surveillance cultures.

\section{Acknowledgements}

Lize-Mari Russo is thanked for excellent technical assistance with this project. SCE is the developer and patent holder of EPI- $\mathrm{V}^{\circledR}$.

\section{References}

[1] Anonymous (1995) Vancomycin Resistant Enterococci in Hospitals in the United Kingdom. Communicable Disease Report (CDR) Weekly, 5, 281.

[2] Centers for Disease Control and Prevention (1995) Recommendations for Preventing the Spread of Vancomycin Resistance. Recommendations of the Hospital Infection Control Practices Advisory Committee (HICPAC). Morbidity and Mortality Weekly Report (MMWR), 44, 1-13.

[3] Chadwick, P.R. and Oppenheim, B.A. (1995) Neomycin Blood Agar as Selective Medium for Vancomycin-Resistant Enterococcus faecium. Journal of Clinical Microbiology, 48, 1068-1070.

[4] CLSI (2011) Performance Standards for Antimicrobial Susceptibility Testing; Twenty-First Informational Supplement. CLSI Document M100-S21. Clinical and Laboratory Standards Institute, Wayne, PA.

[5] Edberg, S.C., Allen, M.J., Smith, D.B. and the National Collaborative Study (1988) National Field Evaluation of a Defined Substrate Method for the Simultaneous Enumeration of Total Coliforms and Escherichia coli from Drinking Water: Comparison with the Standard Multiple Tube Fermentation Method. Applied and Environmental Microbiology, 54, 1595-1601.

[6] Edberg, S.C. and Edberg, M.M. (1988) A Defined Substrate Technology for the Enumeration of Microbial Indicators of Environmental Pollution. Yale Journal of Biology and Medicine, 61, 389-399.

[7] Edberg, S.C., Hardalo, C.J., Kontnick, C. and Campbell, S. (1994) Rapid Detection of Vancomycin-Resistant Enterococci. Journal of Clinical Microbiology, 32, 2182-2184.

[8] Edmond, M.B., Ober, J.F., Weinbaum, D.L., Pfaller, M.A, Hwang, T., Sabford, M.D. and Wenzel, R.P. (1995) Vancomycin-Resistant Enterococcus faecium Bacteremia: Risk Factors for Infection. Clinical Infectious Diseases, 20, 1126-1133.

[9] Facklam, R., Pigott, N., Franklin, R. and Elliott, J. (1995) Evaluation of Three Disk Tests for Identification of Enterococci, Leuconostocs, and Pediococci. Journal of Clinical Microbiology, 33, 885-887.

[10] Gordts, B., Van Landuyt, H., Leven, M., Vandamme, P. and Goossens, H. (1995) Vancomycin-Resistant Enterococci Colonizing the Intestinal Tracts of Hospitalized Patients. Journal of Clinical Microbiology, 33, 2842-2846.

[11] Heath, C.H., Blackmore, T.K. and Gordon, D.L. (1996) Emerging Resistance in Enterococcus spp. Medical Journal of Australia, 164, 116-120.

[12] Lam, S., Singer, C., Tucci, V., Morthland, V.H., Pfaller, M.A. and Isenberg, H.D. (1995) The Challenge of VancomycinResistant Enterococci: A Clinical and Epidemiologic Study. American Journal of Infection Control, 23, 170-180. http://dx.doi.org/10.1016/0196-6553(95)90038-1

[13] Murray, P.R., Baron, E.J., Jorgensen, J.H., Landry, M.L. and Pfaller, M.A. (2007) Manual of Clinical Microbiology. 9th Edition, American Society for Microbiology, Washington, DC.

[14] Edberg, S.C. (2013) Enhanced Reagent for the Detection of L-Pyrrolidonyl- $\beta$-naphthalyamide (PYR) Hydrolysis. 23rd European Congress on Clinical Microbiology and Infectious Diseases, Berlin, 27-30 April 2013.

[15] Noskin, G.A., Cooper, I. and Peterson, L.R. (1995) Vancomycin-Resistant Enterococcus faecium Sepsis Following Persistent Colonization. JAMA Internal Medicine, 155, 1445-1447. http://dx.doi.org/10.1001/archinte.1995.00430130139015

[16] Noskin, G.A., Stosor, V., Cooper, I. and Peterson, L.R. (1995) Recovery of Vancomycin-Resistant Enterococci on Fingertips and Environmental Surfaces. Infection Control and Hospital Epidemiology, 16, 577-581.

[17] Swenson, J.M., Clark, N.C., Ferraro, M.J., Sahm, D.F., Doern, G., Pfaller, M.A., Reller, L.B., Weinstein, M.P., Zabransky, RJ. and Tenover, F.C. (1994) Development of a Standardized Screening Method for Detection of Vancomycin Resistant Enterococci. Journal of Clinical Microbiology, 32, 1700-1704. 
Scientific Research Publishing (SCIRP) is one of the largest Open Access journal publishers. It is currently publishing more than 200 open access, online, peer-reviewed journals covering a wide range of academic disciplines. SCIRP serves the worldwide academic communities and contributes to the progress and application of science with its publication.

Other selected journals from SCIRP are listed as below. Submit your manuscript to us via either submit@scirp.org or Online Submission Portal.
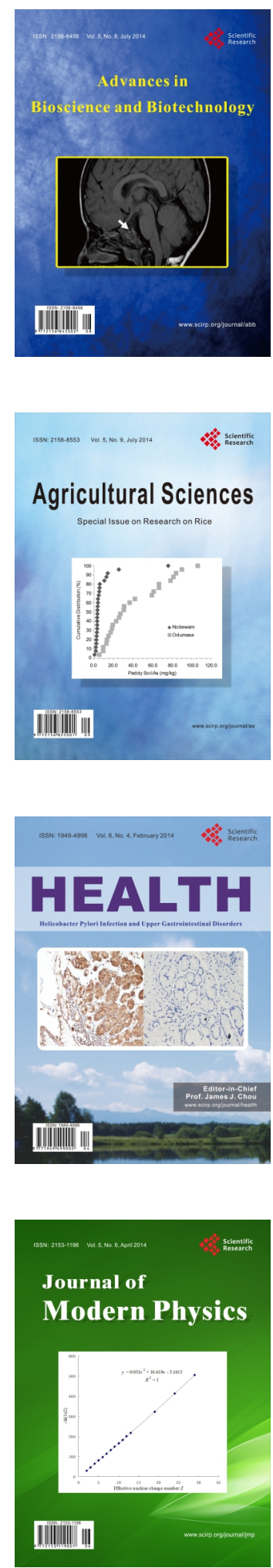
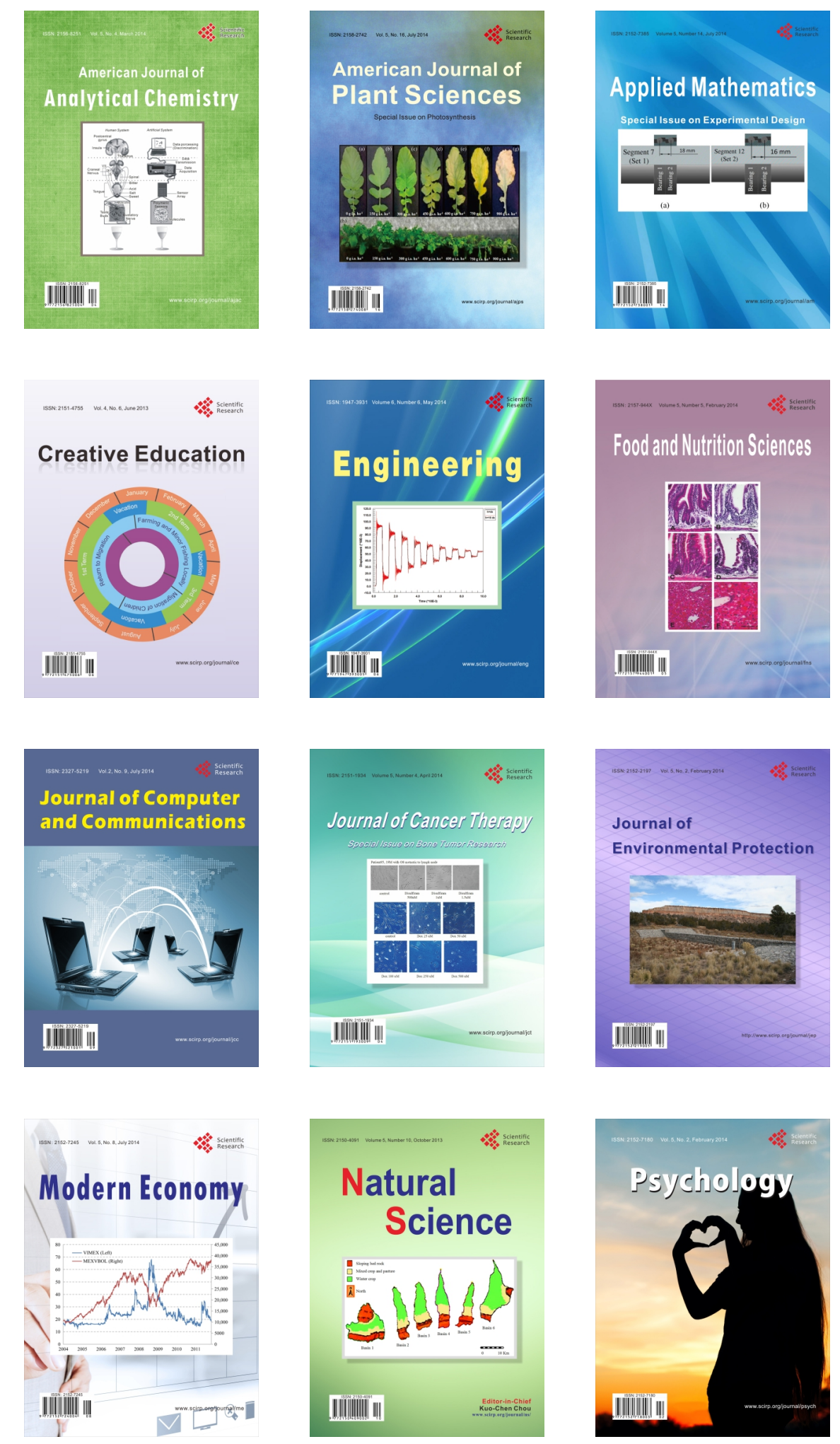